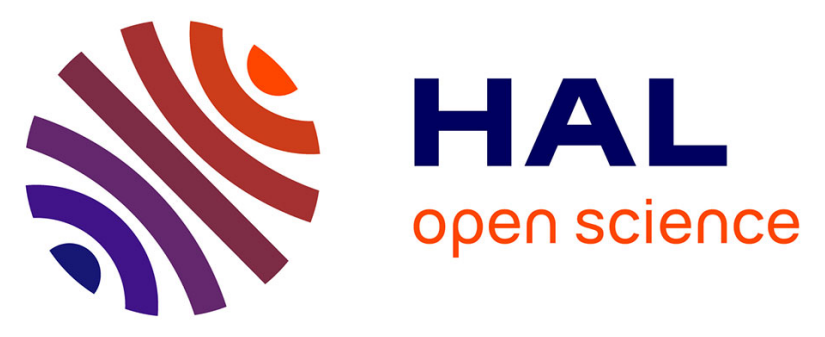

\title{
Evaluation of the kinetic and relaxation time of gentamicin sulfate released from hybrid biomaterial Bioglass-chitosan scaffolds
}

\author{
Eric Wers, Hassane Oudadesse, Bertrand Lefeuvre, Odile \\ Merdrignac-Conanec, Allal Barroug
}

\section{To cite this version:}

Eric Wers, Hassane Oudadesse, Bertrand Lefeuvre, Odile Merdrignac-Conanec, Allal Barroug. Evaluation of the kinetic and relaxation time of gentamicin sulfate released from hybrid biomaterial Bioglasschitosan scaffolds. Applied Surface Science, 2015, 353, pp.200-208. 10.1016/j.apsusc.2015.06.146 . hal-01169302

\section{HAL Id: hal-01169302 \\ https://hal-univ-rennes1.archives-ouvertes.fr/hal-01169302}

Submitted on 22 Sep 2015

HAL is a multi-disciplinary open access archive for the deposit and dissemination of scientific research documents, whether they are published or not. The documents may come from teaching and research institutions in France or abroad, or from public or private research centers.
L'archive ouverte pluridisciplinaire HAL, est destinée au dépôt et à la diffusion de documents scientifiques de niveau recherche, publiés ou non, émanant des établissements d'enseignement et de recherche français ou étrangers, des laboratoires publics ou privés. 


\section{Evaluation of the kinetic and relaxation time of gentamicin sulfate released from hybrid}

\section{biomaterial Bioglass-chitosan scaffolds.}

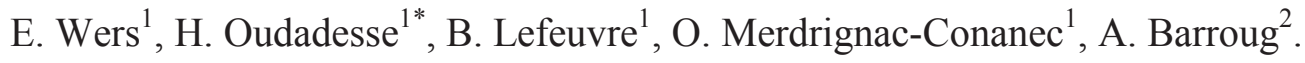

${ }^{1}$ University of Rennes 1, UMR CNRS 6226, 263 av. du Général Leclerc, 35042 Rennes, France.

${ }^{2}$ University Cadi Ayyad. Faculty of Science Semlalia, Marrakech, Maroc

Corresponding author: hassane.oudadesse@univ-rennes1.fr

Abstract: Chitosan scaffolds, combined with bioactive glass 46S6, were prepared to serve as gentamicin sulfate delivery in situ systems for bone biomaterials. This work presents a study about the effect of the ratio chitosan/ bioactive glass $(\mathrm{CH} / \mathrm{BG})$ on the release of gentamicin sulfate and on the bioactivity during in vitro experiments.

SEM observations allowed understanding the bond between the glass grains and the chitosan matrix. In vitro results showed that scaffolds form a hydroxyapatite $(\mathrm{HA}) \mathrm{Ca}_{10}\left(\mathrm{PO}_{4}\right)_{6}(\mathrm{OH})_{2}$ after 15 days of immersion in a simulated body fluid (SBF).

The interest of this study is to see that the increase of the content of bioactive glass in the chitosan matrix slows the release of gentamicin sulfate in the liquid medium. Starting concentration of gentamicin sulfate has an influence on the relaxation time of the scaffolds. Indeed, an increasing concentration delays the return to a new equilibrium. Contents of chitosan and bioactive glass do not affect the relaxation time. Synthesized scaffolds could be adapted to a clinical situation: severity and type of infection, weight and age of the patient.

Keywords: Scaffolds, Drug delivery system, Relaxation time, Chitosan, Gentamicin sulfate. 


\section{Introduction}

Bone loss or failure resulting from a disease or an accident is an important problem in the health field. In the maxillofacial and orthopedic surgery, metal prosthesis, ceramics and other synthetic biomaterials are widely used to bone repair. Nowadays, tissue engineering promises alternative approaches to repair the loss or malfunction of a tissue or an organ [1]. Indeed, a lot of porous scaffolds synthesized with different biodegradable polymers have been fabricated and used for tissue engineering of liver [2], nerve [3] and bone [4]. Natural polymers already have been studied using lyophilization method [5]: alginate [6], collagen and other synthetic polymers as polyvinyl alcohol [7]. Chitosan (figure 1) presents important biological characteristics as biocompatibility, biodegradability, non-toxicity, affinity to proteins, antibacterial, antitumoral properties [8-10]. It used for a lot of medical applications as sutures, bone substitutes and drug delivery [11]. In contrast to all other biodegradable polymers, chitosan is the only one exhibiting a cationic character rendering it unique among all others. The cationic character being based on its primary amino groups is responsible for various properties and subsequently for its use in drug delivery systems [12]. Studied scaffolds were reinforced by the bioactive glass 46S6. This glass can create a hydroxyapatite layer on its surface when it is immersed in SBF [13-14] and allow creating an intimate bond with the bone tissue. In a previous study, the comparison of the behavior of pure glass and composite glass chitosan highlighted the effects of chitosan on the kinetic of chemical reactivity and bioactivity. The advantages of the novel structure of hybrid biomaterial 46S6-chitosan lead to the acceleration of the two parameters compared to pure glass 46S6 [14]. Gentamicin-sulfate (figure 2) was combined with these hybrid biomaterials because it is active against Staphylococcus aureus responsible for osteomyelitis [15-16]. Gentamicin sulfate belong aminoglycoside class of bactericidal antibiotic [17]. The use of antibiotic delivery 
systems for treatment of bone infection is a subject in full development. The poor circulation of blood in the osseous tissue makes necessary the supply of great amount of antibiotics to reach the adequate therapeutic level in the affected region. These systems allow the release by diffusion of an antibiotic through a biodegradable polymer matrix [18-21]. Some studies showed that different stimuli as temperature or $\mathrm{pH}$ [18] involve the release of the drug [22-25]. The present study gives special attentions to:

i) The synthesis of chitosan/bioactive glass/gentamicin sulfate scaffolds and their physicochemical characterizations;

ii) The modifications on the surface of scaffolds after immersion in SBF and the controlled release of gentamicin sulfate evaluated by UV-spectrophotometry.

iii) The elaboration of mathematic models and the interpretation of the time of relaxation concerning the release of gentamicin sulfate.

\section{Materials and methods}

\subsection{Preparation of scaffolds}

The synthesis of scaffolds is divided in three main steps (figure 3).

First, the bioactive glass $46 \mathrm{~S} 6$ was prepared from sodium metasilicate $\left(\mathrm{Na}_{2} \mathrm{SiO}_{3}\right)$, silicon oxide $\left(\mathrm{SiO}_{2}\right)$, calcium metasilicate $\left(\mathrm{CaSiO}_{3}\right)$ and sodium metaphosphate $\left(\mathrm{Na}_{3} \mathrm{P}_{3} \mathrm{O}_{9}\right)$. It is composed of $46 \%$ of $\mathrm{SiO}_{2}, 24 \%$ of $\mathrm{CaO}, 24 \%$ of $\mathrm{Na}_{2} \mathrm{O}$ and $6 \%$ of $\mathrm{P}_{2} \mathrm{O}_{5}$. It was synthesized by the melting process as described in a previous work [26]. Obtained glasses were grinded and sift to obtain a fine granulometry less than $40 \mu \mathrm{m}$. The second step has consisted to dissolve $3 \mathrm{~g}$ of chitosan powder, with a medium molecular weight, in acetic acid solution $1 \% \mathrm{v} / \mathrm{v}$. The solution was stirred under magnetic stirring at room temperature during 24 hours in order to dissolve all the 
chitosan powder. The final step is the preparation of three scaffolds: $2 \mathrm{CH}-1 \mathrm{BG}, 1 \mathrm{CH}-1 \mathrm{BG}$ and 1CH-2BG presenting different ratios chitosan/glass $(\mathrm{CH} / \mathrm{BG})$ (table 1). The glass was added in the chitosan solution. The mixtures were homogenized for 24 hours in an ultrasonic bath. To elaborate scaffolds with gentamicin sulfate, the antibiotic was added in the mixtures. In this work, scaffolds were synthesized with $1 \% \mathrm{w} / \mathrm{v}$ and $3 \% \mathrm{w} / \mathrm{v}$ of gentamicin sulfate. These concentrations have been chosen to avoid reaching the threshold of toxicity of gentamicin sulfate. Indeed, it can be highly nephrotoxic, particularly if multiple doses accumulate during treatment.

Once the homogenization of chitosan/bioactive glass/gentamicin sulfate completed, the solutions were cast into well-plates. They were frozen at $-20^{\circ} \mathrm{C}$ for all-night to frozen the core of the material and placed in a freeze-dryer at 0.65 mbar at $-60^{\circ} \mathrm{C}$ during 24 hours to remove all solvents in samples. Obtained scaffolds were washed in a $\mathrm{NaOH}$ solution $0.4 \% \mathrm{w} / \mathrm{v}$ and distilled water to eliminate traces of acetic acid. They were frozen and lyophilized as previously stated. Finally, scaffolds of $13 \mathrm{~mm}$ of diameter were obtained with different amounts of chitosan and bioactive glass.

\subsection{In vitro evaluation of the bioactivity}

In vitro assays, as described in a previous work [14], were realized in a SBF whose the chemical composition is similar to the blood plasma (table 2) [14, 27].

$30 \mathrm{mg}$ of powder samples were immersed during 1,2, 7, 15 and 30 days in triplicate in $60 \mathrm{~mL}$ of $\mathrm{SBF}$ and maintained under controlled stirring at $50 \mathrm{rpm}$. At the end of soaking time, the powder samples removed and rinsed with deionized water to stop the exchange reactions. The powder samples dried and stored for further investigation of the formation of HA layer on the surface of 
powder samples. This was verified by fourier transform infrared spectroscopy (FTIR, Bruker equinox 55 spectrophotometer) and X-ray diffraction (XRD, Bruker AXS D8 Advance diffractometer). The SBF solutions were stored in fridge to evaluate the ionic exchanges between materials and SBF by ICP-OES (Spectro Ciros Vision Ametek).

\subsection{In vitro study of the release of gentamicin sulfate}

The controlled release of gentamicin sulfate was studied after immersion of scaffolds of $300 \mathrm{mg}$ ( $\pm 5 \mathrm{mg}$ ) in $10 \mathrm{~mL}$ of a physiological saline solution (BioWhittaker ${ }^{\circledR}$ Dulbecco's PBS) without calcium and magnesium to avoid the chemical reaction of bioactivity. Its buffering capacity is based on the dihydrogen/hydrogen pair which is also one of three major mechanisms for maintaining blood $\mathrm{pH}$ :

$$
\mathrm{HPO}_{4}{ }^{2-}+\mathrm{H}^{+}=\mathrm{H}_{2} \mathrm{PO}_{4}{ }^{-}
$$

The release of gentamicin sulfate was studied after 5, 10, 20, 30 minutes and 1, 2, 6 hours in triplicate. These notices were chosen because some studies have proved that gentamicin sulfate is released quickly [18-28]. PBS solutions were analyzed at $256 \mathrm{~nm}$ using UV spectrophotometer (Jenway 6705) to measure the concentration of gentamicin sulfate. The blank control is $10 \mathrm{~mL}$ of PBS without materials and the calibration curve was plotted using standards solutions of increasing concentrations of gentamicin sulfate from 1 to $30 \mathrm{mg} \cdot \mathrm{mL}^{-1}$. The results were averaged with standard deviation.

\section{Results and discussions}

\subsection{Surface characterizations of scaffolds}


Porosity is an important characteristic for biomaterials because it supports the cells colonization, the deposit of organic matter and the transport of drugs or molecules for therapeutic uses. It was evaluated by Brunauer-Emmet-Teller (BET) method using Micromeritics ASAP 2010 analyzer. According to the International Union of Pure and Applied Chemistry (IUPAC) classification, the obtained isotherms (figure 4) belong to type H3. The curves of adsorption and desorption form a hysteresis loop. The hysteresis cycle is due to the capillary condensation phenomenon characteristic of a mesoporous material (pore diameter between $2 \mathrm{~nm}$ and less than $50 \mathrm{~nm}$ ). On each hysteresis cycle, shoulders, characteristic of several families of mesopores, are observed at $\mathrm{P} / \mathrm{P}_{0}=0.5$. According to the BET and Barrett-Joyner-Halenda $(\mathrm{BJH})$ methods, the values of specific surface area pore size and pore volume (table 3) were calculated. An increase of specific surface area is observed when the ration $\mathrm{CH} / \mathrm{BG}$ increases: $6.90( \pm 0.07) \mathrm{m}^{2} \cdot \mathrm{g}^{-1}$ for $1 \mathrm{CH}-2 \mathrm{BG}$ scaffolds, $7.60( \pm 0.08) \mathrm{m}^{2} . \mathrm{g}^{-1}$ for $1 \mathrm{CH}-1 \mathrm{BG}$ and $7.90( \pm 0.08) \mathrm{m}^{2} \cdot \mathrm{g}^{-1}$ for $2 \mathrm{CH}-1 \mathrm{BG}$. The same observations for pore volume were registered: $7.00( \pm 0.07) \mathrm{mm}^{3} \cdot \mathrm{g}^{-1}$ for $1 \mathrm{CH}-2 \mathrm{BG}$ scaffolds, $7.40( \pm 0.07) \mathrm{mm}^{3} \cdot \mathrm{g}^{-1}$ for $1 \mathrm{CH}-1 \mathrm{BG}$ scaffolds and $2 \mathrm{CH}-1 \mathrm{BG}$ scaffolds present $8.10( \pm 0.08)$ $\mathrm{mm}^{3} \cdot \mathrm{g}^{-1}$ of pore volume. It was found that the specific surface area and pore volume increase when the introduced content of chitosan increases [14]. Moreover, specific surface area of 46S6 and chitosan are respectively 0.9 and $0.7 \mathrm{~m}^{2} \cdot \mathrm{g}^{-1}$ [14]. The association of chitosan with the bioactive glass $46 \mathrm{~S} 6$ increases the specific surface area. Furthermore, with a high content of chitosan, the average pore diameter also increases. Indeed, 2CH-1BG scaffolds present an average pore diameter of $5.2 \mathrm{~nm}, 1 \mathrm{CH}-1 \mathrm{BG} 3.6 \mathrm{~nm}$ and $1 \mathrm{CH}-2 \mathrm{BG} 4.0 \mathrm{~nm}$.

SEM observations were performed using a Jeol JSM 6301F scanning electron microscope. The surfaces of scaffolds before immersion in the SBF were registered. For all scaffolds, pores are 
visible (figures 5.a to 5.c). Bioactive glass particles seem to be pasted on the chitosan matrix for each type of scaffolds (figures 5.d to 5.f). All scaffolds have smooth chitosan matrix which coats the larger glass grains. Concerning the porosity:

$-2 \mathrm{CH}-1 \mathrm{BG}$ scaffolds possess a wide variety of pores (fine and ample pores), that explains why they have a pore volume and an average pore diameter larger than the other two.

$-1 \mathrm{CH}-1 \mathrm{BG}$ scaffolds present the same morphology of pores compared to $2 \mathrm{CH}-1 \mathrm{BG}$ scaffolds but they have a less homogeneous surface.

-1CH-2BG scaffolds have a more homogeneous surface but they present wider pores, this could explain an average pore diameter greater than $1 \mathrm{CH}-1 \mathrm{BG}$ scaffolds but a smaller pore volume.

These observations clearly confirm the obtained results by adsorption of $\mathrm{N}_{2}$. These variations of porosity function of the ration $\mathrm{CH} / \mathrm{BG}$ could expand the capacity of uses of these biomaterials for medical applications.

\subsection{Characterizations of scaffolds after in vitro assays}

The XRD patterns of $1 \mathrm{CH}-1 \mathrm{BG}, 1 \mathrm{CH}-2 \mathrm{BG}$, and 2CH-1BG scaffolds after 30 days of immersion in the SBF are presented in figure 6. Several references as $46 \mathrm{~S} 6$, chitosan scaffolds before immersion were chosen to observe an eventual change in the structure [27-32]. The hydroxyapatite was chosen as reference to present its eventual formation on materials. A halo of diffraction is observed for $2 \mathrm{CH}-1 \mathrm{BG}$ scaffolds between 15 and $25\left(2 \theta^{\circ}\right)$ due to the high amount of chitosan. After 30 days of immersion in the SBF, the formation of hydroxyapatite is confirmed by the appearance of two peaks of diffraction: at $25.9\left(2 \theta^{\circ}\right)$ corresponding to the $(002)$ apatite reflection and $31.8\left(2 \theta^{\circ}\right)$ corresponding to the (211) apatite reflection [33]. For all the scaffolds, the bioactivity is observed from 15 days of immersion. Therefore, the content of 46S6 
does not have a significant effect on the bioactivity of scaffolds. Indeed, the hydroxyapatite appears for each scaffold. The bioactive glass releases calcium, phosphorus and silicon ions in the SBF and allows the formation of hydroxyapatite. The ionic exchanges study was performed by using ICP-OES. However, a better crystallization of hydroxyapatite is observed for $2 \mathrm{CH}$ 1BG. This phenomenon may be related to the specific surface area of the samples. Having a larger specific surface area and a larger pore volume, $2 \mathrm{CH}-1 \mathrm{BG}$ scaffolds promotes the flow of the SBF through the material, favoring ion exchanges and forming a better crystallized hydroxyapatite.

In order to observe eventual structural modifications of our scaffolds after soaking in SBF solution, the FTIR spectra after 30 days of immersion are presented in figure 7. Characteristics bands are resumed in table 4 .

The disappearance of the band at $807 \mathrm{~cm}^{-1}$ characteristic of the symmetric Si-O-Si stretching bond is observed. For all the scaffolds, after 30 days of immersion, the formation of hydroxyapatite is confirmed by the bands corresponding to the P-O chemical bond at 563, 605 $\mathrm{cm}^{-1}$ [34] and two slight shoulders at 958 and $1105 \mathrm{~cm}^{-1}$ are observed. At $1655 \mathrm{~cm}^{-1}$, a band characteristic of (Amide $\mathrm{I}: \mathrm{vC}=\mathrm{O}$ ) function appears at the expense of the disappearance of the band at $1568 \mathrm{~cm}^{-1}$. Furthermore, the bands corresponding to (Amide $: \gamma \mathrm{N}-\mathrm{H}$ ) chemical bond at 645 and $620 \mathrm{~cm}^{-1}$ disappear, ditto to the band at $522 \mathrm{~cm}^{-1}$ characteristic of the symmetric Si-O-Si stretching bond.

The bands characteristics of $\mathrm{P}-\mathrm{O}$ bonds of hydroxyapatite for $2 \mathrm{CH}-1 \mathrm{BG}$ scaffolds are more intense and are characteristics of a better crystallization. This confirms the hypothesis of the results obtained by XRD. 
These results confirm the bioactive character of scaffolds. ICP-OES analyses were performed to measure the ionic exchanges between scaffolds and SBF and to understand the mechanism of bioactivity.

After immersion in the SBF solution, SEM micrographs (figure 8) do not reveal the layer of hydroxyapatite. However, modifications of surfaces are observed. They present a creamy aspect after immersion. The glass grains, present on the surface, have disappeared. The coated glass grains are more visible because the chitosan matrix is torn by location. The hydroxyapatite, detected by XRD and FTIR, is not observed. It may be that it has formed inside the material under the chitosan matrix.

The chemical elements $\mathrm{Si}, \mathrm{Ca}$ and $\mathrm{P}$ have been carefully selected for quantitative analyses by ICP-OES. This physical method presents a high sensitivity and allows having the kinetic of bioactivity. Indeed, silicon is an indicator of the dissolution of bioactive glass while calcium and phosphorus help to understand the formation of calcium phosphate [35-36]. These chemical elements were measured in the SBF solution at different periods $(2,4,8$ and 16 hours and 1, 2, 7, 15 and 30 days).

Silicon (figure 9.a) is released quickly during the first hours going from 0 to $19 \mathrm{ppm}$ on average. It is released up to 30 days. The $1 \mathrm{CH}-2 \mathrm{BG}$ scaffolds, containing more bioactive glass, release much silicon in the SBF (up to $26 \mathrm{ppm}$ ). $1 \mathrm{CH}-1 \mathrm{BG}$ and $2 \mathrm{CH}-1 \mathrm{BG}$ scaffolds release respectively 19.5 and 14 ppm after 30 days of immersion. Indeed, the bioactive glass grains are locked in the chitosan matrix which explains the lower release. These results also prove that the silica network of the 46S6 is progressively degraded in the SBF solution.

For calcium (figure 9.b) and phosphorus (figure 9.c) releases, the same looks are distinguished for scaffolds. Indeed, from 2 hours up to 30 days, calcium and phosphorus concentrations 
decrease continually. It means that there is a consumption of calcium and phosphorus by scaffolds. However, more the content of bioactive glass in scaffolds is high and more calcium and phosphorus are consumed. In contrast, more the amount of chitosan is important, more calcium and phosphorus are consumed slowly. The slower kinetics of absorption of calcium and phosphorus for 2CH-1BG scaffolds could explain the better crystallization observed by XRD and FTIR. Indeed, crystallization is a function of time. It is possible that this low kinetics of absorption of calcium and phosphorus suitable for better crystallization of hydroxyapatite. Moreover, this slowdown of absorption can be explained by the coating of glass grains by the chitosan matrix. Indeed, the chitosan is introduced in a high amount for $2 \mathrm{CH}-1 \mathrm{BG}$ scaffolds and glass grains trapped in the chitosan absorb more hardly the necessary chemical elements for the formation of hydroxyapatite. However, the integration of bioactive glass with its high bioactivity [35-36] promotes the consumption of calcium and phosphorus to create crystals of hydroxyapatite. Therefore, it explains the formation of hydroxyapatite in materials from 15 days and the ionic exchanges for each scaffold.

All these results emphasize the phenomena of bioactivity of scaffolds. XRD and FTIR spectroscopy reveal the appearance of a hydroxyapatite for each scaffold. ICP-OES gives the ionic exchanges during this phenomenon. Silicon ions are released; calcium and phosphorus ions are consumed by scaffolds according to the content of chitosan and bioactive glass up to 30 days of immersion explaining the formation of hydroxyapatite. This hydroxyapatite is more or less well crystallized according to the chemical composition. With their different kinetic of bioactivity, these materials may be suitable for various medical applications. 
The originality of these materials is that they can be elaborated with a drug in order to treat locally an infection. Scaffolds have been charged with gentamicin sulfate and the study of the release of this drug was undertaken.

\subsection{Kinetic of the controlled release of gentamicin sulfate}

Local antibiotic therapy has been already used in all types of bone infections. The aim of this investigation was to study the effect of the content of chitosan and bioactive glass on the kinetic of release of gentamicin sulfate.

The curves of release of gentamicin sulfate present same appearance (figure 10.a and 10.b): Mathematical relations (table 5 and 6), corresponding to the liberation of drug in the PBS solution versus time of immersion, were established. In this relation, the relaxation time parameter $(\boldsymbol{\tau})$ characteristic of scaffolds was deducted. $\tau$ is related to the response of the system studied (scaffold) to an instantaneous disturbance (immersion in PBS). $\tau$ represents the order of magnitude of time at which the new equilibrium is reached (limit concentration $\mathrm{C}_{0}$ ).

The release of gentamicin sulfate, in the PBS solution, follows a law of the type:

$$
C_{g}=C_{0} \times\left[1-\exp \left(-\frac{t}{\tau}\right)\right]
$$

Where:

$\mathbf{C}_{\mathbf{g}}$ is the gentamicin sulfate concentration, $\mathbf{C}_{\mathbf{0}}$ is the gentamicin sulfate limit concentration, $\mathbf{t}$ the immersion time and $\tau$ the relaxation time of the system. 
Scaffolds, with $1 \%$ of gentamicin sulfate, need to 29 minutes to reach their new equilibrium versus 38 minutes for scaffolds with $3 \%$ of gentamicin sulfate.

For scaffolds doped with $1 \%$ of gentamicin sulfate (figure 10.a), the release is fast up to 60 minutes of immersion. The gentamicin sulfate concentration goes from 0 to: $5.6 \mathrm{mg} \cdot \mathrm{mL}^{-1}$ for 2CH-1BG, $3.7 \mathrm{mg} \cdot \mathrm{mL}^{-1}$ for $1 \mathrm{CH}-1 \mathrm{BG}$ and $1.7 \mathrm{mg} \cdot \mathrm{mL}^{-1}$ for $1 \mathrm{CH}-2 \mathrm{BG}$. A stability of release is observed after 60 minutes. At 360 minutes, the concentration of gentamicin sulfate reaches 5.9 mg.mL $L^{-1}, 4.0 \mathrm{mg} \cdot \mathrm{mL}^{-1}$ and $1.9 \mathrm{mg} \cdot \mathrm{mL}^{-1}$ for respectively $2 \mathrm{CH}-1 \mathrm{BG}, 1 \mathrm{CH}-1 \mathrm{BG}$ and $1 \mathrm{CH}-2 \mathrm{BG}$. Concerning scaffolds doped with $3 \%$ of gentamicin sulfate (figure 10.b), the release also is fast up to 120 minutes. The concentration of gentamicin sulfate goes from 0 to: $11.9 \mathrm{mg} \cdot \mathrm{mL}^{-1}$ for 2CH-1BG, $5.6 \mathrm{mg} \cdot \mathrm{mL}^{-1}$ for $1 \mathrm{CH}-1 \mathrm{BG}$ and $1 \mathrm{CH}-2 \mathrm{BG}$ scaffolds. After 120 minutes, a stability of release is observed and the concentration of gentamicin sulfate reaches $12.3 \mathrm{mg} \cdot \mathrm{mL}^{-1}$ for $2 \mathrm{CH}$ 1BG, $6.5 \mathrm{mg} \cdot \mathrm{mL}^{-1}$ for $1 \mathrm{CH}-1 \mathrm{BG}$ and $1 \mathrm{CH}-2 \mathrm{BG}$ scaffolds.

A difference of a factor 2 is observed between the data of concentration of gentamicin sulfate for scaffolds with $1 \%$ of gentamicin sulfate and them with $3 \%$ of gentamicin sulfate. Several characteristics of scaffolds can explain the delivery of gentamicin sulfate such as their porosity and their specific area [13]. Indeed, 2CH-1BG scaffolds, having a larger specific surface area $\left(7.9 \mathrm{~m}^{2} \cdot \mathrm{g}^{-1}\right)$ and a larger pore volume $\left(8.1 \mathrm{~mm}^{3} \cdot \mathrm{g}^{-1}\right)$, release more gentamicin sulfate (with either 1 or $3 \%$ ) than the two other types of scaffolds; followed by $1 \mathrm{CH}-1 \mathrm{BG}$ scaffolds and $1 \mathrm{CH}-2 \mathrm{BG}$ scaffolds. It has also been reported in several studies that the nature of the antibiotic were involved in the kinetics of release [13]. Indeed, the gentamicin sulfate presents an early release due to its hydrophilic character [13].

For all scaffolds, the variations of the content of bioactive glass and that of chitosan do not impact the relaxation time. In contrast, the concentration of gentamicin sulfate increases the 
relaxation time. The limit concentration depends on the content of bioactive glass and chitosan. The presence of a high content of chitosan increases the limit concentration $\mathrm{C}_{0}$.

These results are interesting because for scaffolds doped with $1 \%$ or $3 \%$ of gentamicin sulfate, different behaviors are observed. Indeed, $2 \mathrm{CH}-1 \mathrm{BG}$ has a better kinetic of release that $1 \mathrm{CH}-1 \mathrm{BG}$ and $1 \mathrm{CH}-2 \mathrm{BG}$. The pore volume and surface area, due to the introduction of different contents of chitosan and bioactive glass may explain this phenomenon. The scaffolds doped with $1 \%$ gentamicin sulfate have a stable release from 1 hour of immersion while for scaffolds doped with $3 \%$ gentamicin sulfate; stabilization is observed from 2 hours of immersion in PBS. Moreover, the introduction of a high concentration of drug causes a later stabilization and also more important release of drug. The hydrophilic character of chitosan and gentamicin sulfate may explain the high release of gentamicin sulfate during the first minutes. The rapid release of gentamicin sulfate for both concentrations can be explained by the chemical bonds created between chitosan and gentamicin sulfate. The literature does not mention the possible connections but we can formulate a hypothesis. The most plausible hypothesis is that hydrogen bonds are formed between the $\mathrm{OH}$ groups of chitosan (figure 1) and gentamicin sulfate (figure 2) creating a "zipper effect". Indeed, hydrogen bonds involve a hydrogen atom and an electronegative atom (such as oxygen). Hydrogen bonds have a low intensity (20 times weaker than the covalent bonds). This hypothesis could therefore justify and explain the rapid release of gentamicin sulfate from the first minutes of immersion of the scaffolds in PBS.

\section{Conclusions}

Porous $\mathrm{CH}-\mathrm{BG}$ scaffolds were developed for use in bone tissue engineering applications. The antibiotic gentamicin sulfate was entrapped into the scaffolds via the freeze-drying method to 
confer them the drug release capability. The increase of specific surface area, average pore diameter and pore volume are observed when the content of chitosan is more important than that of bioactive glass 46S6. The in vitro assays of scaffolds in PBS show than the release of gentamicin sulfate increases with these three parameters. This drug was released in a controlled manner. The release rate, the relaxation time of scaffolds and the limit concentration were also dependent on the gentamicin sulfate concentration introduced in the beginning. Present $\mathrm{CH}-\mathrm{BG}$ scaffolds, exhibiting a bioactive character in SBF and controlled release ability of an antibiotic, are proposed for bone tissue engineering. These biomaterials could be adapted at a clinical application and according to the advance of infection to treat. Scaffolds represent a new type of biomaterials in the field of therapeutic materials for the tissue engineering.

\section{Acknowledgements}

Authors would like to acknowledge J. Le Lannic and F. Perron (CMEBA, University of Rennes 1) for all micrographs. R. Ollitrault and E. Jullion for their help for the UV spectrophotometer analyses. CNRST, Maroc for the support by FINCOME program. 


\section{References}

[1] Chen G, Ushida T, Tateishi T. Scaffold design for tissue engineering. Macromol Bioscience 2002;2:67-77.

[2] Kneser U, Kaufmann PM, Fiegel HC, Pollok JM, Kluth D, Herbst H, Rogiers X. Long-term differentiated function of heterotopically transplanted hepatocytes on three-dimensional polymer matrices. J Biomed Mater Res 1999;47:494-503.

[3] Hadlock T, Sundback C, Hunter D, Cheney M, Vacanti JP. A polymer foam conduit seeded with Schwann cells promotes guided peripheral nerve regeneration. Tissue Eng 2000;6:119-127. [4] Ishaug SL, Crane GM, Miller MJ, Yasko AW, Yaszemski MJ, Mikos AG. Bone formation by three-dimensional stromal osteoblast culture in biodegradable polymer scaffolds. J Biomed Mater Res 1997;6:17-28.

[5] Kim IY, Seo SJ, Moon HS, Yoo MK, Park IY, Kim BC, Cho CS. Chitosan and its derivatives for tissue engineering. Biotechnol Adv 2008;26:1-21.

[6] Barbosa MA, Granja PL, Barrias CC, Amaral IF. Polysaccharides as scaffolds for bone regeneration. ITBM-RBM 2005;26:212-217.

[7] Nie L, Chen D, Suo J, Zou P, Feng S, Yang Q, Yang S, Ye S. Physicochemical characterization and biocompatibility in vitro of biphasic calcium phosphate/polyvinyl alcohol scaffolds prepared by freeze-drying method for bone tissue engineering applications. Colloid Surface B 2012;100:169- 176.

[8] Nishimura K, Nishimura S, Nishi N, Saiki I, Tokura S, Azuma I. Immunological activity of chitin and its derivatives. Vaccine 1984;2:93-99. 
[9] Okamoto Y, Watanabe M, Miyatake K, Morimoto M, Shigemasa Y, Minami S. Effects of chitin/chitosan and their oligomers/monomers on migrations of fibroblasts and vascular endothelium. Biomaterials 2002;23:1975-1979.

[10] Mori T, Irie Y, Nishimura SI, Tokura S, Matsura M, Okumura M. Endothelial cell responses to chitin and its derivatives. J Biomed Mater Res 1998;43:469-472.

[11] Vandevord PJ, Matthew HWT, DeSilva SP, Mayton L, Wu B, Wooley PH. Evaluation of the biocompatibility of a chitosan scaffold in mice. J Biomed Mater Res 2002;59:585-590.

[12] Bernkop-Schnurch A, Dunnhaupt S. Chitosan-based drug delivery systems. Eur J Pharm Biopharm $2012 ; 81: 463-69$.

[13] Lambott JC, Thomazeau H, Cathelineau G, Lancien G, Minet J, Langlais F. Phosphate tricalcique, vecteur d'antibiotiques: étude sur foyer d'ostéomyélite expérimentale chez le lapin. Chirurgie 1998;123:572-579.

[14] Oudadesse H, Wers E, Bui XV, Roiland C, Bureau B, Akhiyat I, Mostafa A, Chaair H, Benhayoune H, Fauré J, Pellen-Mussi P. Chitosan effects on glass matrices evaluated by biomaterial. MAS-NMR and biological investigations. Korean J Chem Eng 2013;9:1775-1783

[15] Zhang Y, Zhang M. Calcium phosphate/chitosan composite scaffolds for controlled in vitro antibiotic drug release. J Biomed Mater Res 2002;62:378-386.

[16] Brouard S, Lelan J, Lancien G, Bonnaure M, Cormier M, Langlais F. Phosphate tricalcique vecteur d'antibiotiques : gentamicine et vancomycine. Caractérisations physico-chimiques in vitro, étude de la porosité du matériau et du relargage de la gentamicine et de la vancomycine. Chirurgie 1997;122:397-403.

[17] Balakumar P, Rohilla A, Thangathirupathi A. Gentamicin-induced nephrotoxicity: Do we have a promising therapeutic approach to blunt it ?. Pharmacol Res 2010;62:179-186. 
[18] Pichavant L, Amador G, Jacqueline C, Brouillaud B, Heroguez V, Durrieu MC. pHcontrolled delivery of gentamicin from orthopedic devices preventing nosocomial infections. $\mathrm{J}$ Control Release 2012;162:373-381.

[19] Habraken WJEM, Wolke JGC, Jansen JA. Ceramic composites as matrices and scaffolds for drug delivery in tissue engineering. Adv Drug Deliver Rev 2007;59:234-248.

[20] Chang HI, Perrie Y, Coombes AGA. Delivery of the antibiotic gentamicin sulphate from precipitation cast matrices of polycaprolactone. J Control Release 2006;110:414-421.

[21] Wang G, Liu SJ, Ueng SWN, Chan EC. The release of cefazolin and gentamicin from biodegradable PLA/PGA beads. Int J Pharm 2004;273:203-212.

[22] Anal AK. Stimuli-induced Pulsatile or Triggered Release Delivery Systems for Bioactive Compounds. Recent Pat Endocr Metab Drug Discov 2007;1:83-90.

[23] Al-Abd AM, Hong KY, Song SC, Kuh HJ. Pharmacokinetics of doxorubicin after intratumoral injection using a thermosensitive hydrogel in tumor-bearing mice. J Control Release 2010;142:101-107.

[24] Peng KT, Chen CF, Chu IM, Li YM, Hsu WH, Hsu RW, Chang PJ. Treatment of osteomyelitis with teicoplanin-encapsulated biodegradable thermosensitive hydrogel nanoparticles. Biomaterials 2010;31:5227-5236.

[25] Sirivisoot S, Pareta R, Webster TJ. Electrically controlled drug release from nanostructured polypyrrole coated on titanium. Nanotechnology 2011;22:085101.

[26] Wers E, Oudadesse H. Thermal behaviour and excess entropy of bioactive glasses and Zndoped glasses. J Therm Anal Calorim 2014;115:2137-2144.

[27] Kokubo T, Kushitani H, Sakka S, Kitsugi T, Yamamuro T. Solutions able to reproduce in vivo surface-structure changes in bioactive glassceramic A-W. J Biomed Mater Res 1990;24: 
721-734.

[28] Bochaton C, Rochegude S, Roubille R. Les aminoglycosides. Lyon Pharm. 1997;48:226239.

[29] Zhang Y. Preparation of electrospun chitosan/poly(vinyl alcohol) membranes. Colloid Polym Sci 2007;285:855-863.

[30] Silva SS. Functional nanostructured chitosan-siloxane hybrids. J Mater Chem 2005;15: 3952-3961.

[31] Mansur SH. Nanostructured ploy(vinyl alcohol)/bioactive glass and poly(vinyl alcohol)/chitosan/bioactive glass hybrid scaffolds for biomedical applications. Chem Eng J 2008;137:72-83.

[32] Peitl O, Dutra Zanotto E, Hench LL. Highly bioactive $\mathrm{P}_{2} \mathrm{O}_{5}-\mathrm{Na}_{2} \mathrm{O}-\mathrm{CaO}-\mathrm{SiO}_{2}$ glass ceramics. J Non-Cryst Solids 2001;292:115-126.

[33] Ashok M, Sundaram NM, Kalkur SN. Crystallization of hydroxyapatite at physiological temperature. Mater Lett 2003;57:2066-2070.

[34] Handke M, Sitarz M, Rokita M, Galuskin E. Vibrational spectra of phosphate-silicate biomaterials. J Mol Struct 2003;651: 39-54.

[35] Oudadesse H, Dietrich E, Bui XV, Le Gal Y, Pellen P, Cathelineau G. Enhancement of cells proliferation and control of bioactivity of strontium doped glass. Appl Surf Sci 2011;257: 85878593.

[36] Dietrich E, Oudadesse, Lucas-Girot A, Mami M. H. In vitro bioactivity of melt-derived glass 46S6 doped with magnesium. J Biomed Mater Res A 2009;88:1087-1096. 


\section{Caption Figures}

Figure 1: Chemical formula of chitosan

Figure 2: Chemical formula of gentamicin sulfate

Figure 3: Steps in the synthesis of scaffolds

Figure 4: BET analysis of scaffolds

Figure 5: SEM micrographs (x700) of scaffolds before soaking: a $1 \mathrm{CH}-1 \mathrm{BG}, \mathbf{b} 1 \mathrm{CH}-2 \mathrm{BG}, \mathbf{c}$ $2 \mathrm{CH}-1 \mathrm{BG}$ and (x5000): d $1 \mathrm{CH}-1 \mathrm{BG}$, e $1 \mathrm{CH}-2 \mathrm{BG}, \mathbf{f} 2 \mathrm{CH}-1 \mathrm{BG}$

Figure 6: Diffractograms of scaffolds before and after immersion in SBF

Figure 7: FTIR spectra of scaffolds before and after immersion in SBF

Figure 8: SEM micrographs (x5000) of scaffolds after 30 days of soaking in SBF: d 1CH-1BG, e $1 \mathrm{CH}-2 \mathrm{BG}, \mathbf{f} 2 \mathrm{CH}-1 \mathrm{BG}$

Figure 9.a Si concentration after immersion at different times in SBF

Figure 9.b Ca concentration after immersion at different times in SBF

Figure 9.c P concentration after immersion at different times in SBF

Figure 10.a Release of gentamicin after immersion in the PBS

Figure 10.b Release of gentamicin after immersion in the PBS

\section{Highlights}

- The chemical composition of scaffolds influences the release of gentamicin sulfate.

- The concentration of gentamicin sulfate has an influence on the relaxation time of scaffolds.

- An increasing concentration of gentamicin sulfate delays the return to a new equilibrium. 


\begin{tabular}{|c|c|c|}
\hline Scaffolds & Content of chitosan $(\mathrm{g})$ & Content of bioactive glass $(\mathrm{g})$ \\
\hline $2 \mathrm{CH}-1 \mathrm{BG}$ & 3 & 1.5 \\
\hline $1 \mathrm{CH}-1 \mathrm{BG}$ & 3 & 3 \\
\hline $1 \mathrm{CH}-2 \mathrm{BG}$ & 3 & 6 \\
\hline
\end{tabular}

Table 1: Chemical composition of scaffolds

\begin{tabular}{|c|c|c|c|c|c|c|c|c|}
\hline Ions & $\mathrm{Na}^{+}$ & $\mathrm{K}^{+}$ & $\mathrm{Mg}^{2+}$ & $\mathrm{Ca}^{2+}$ & $\mathrm{Cl}^{-}$ & $\mathrm{HCO}_{3}{ }^{-}$ & $\mathrm{HPO}_{4}{ }^{2-}$ & $\mathrm{SO}_{4}{ }^{2-}$ \\
\hline SBF & 142,0 & 5,0 & 1,5 & 2,5 & 147,8 & 4,2 & 1,0 & 0,5 \\
\hline Plasma & 142,0 & 5,0 & 1,5 & 2,5 & 103,0 & 27,0 & 1,0 & 0,5 \\
\hline
\end{tabular}

Table 2: Ionic concentrations of SBF and human blood plasma (mM)

\begin{tabular}{|c|c|c|c|}
\hline $\begin{array}{c}\text { Scaffolds } \\
\text { Specific Surface Area } \\
\left(\mathrm{m}^{2} \cdot \mathrm{g}^{-1}\right)\end{array}$ & 2CH-1BG & 1CH-1BG & 1CH-2BG \\
\hline $\begin{array}{r}\text { Average Pore Diameter } \\
(\mathrm{nm})\end{array}$ & $5.90 \pm 0.08$ & $7.60 \pm 0.08$ & $6.90 \pm 0.07$ \\
\hline Pore Volume $\left(\mathrm{mm}^{3} \cdot \mathrm{g}^{-1}\right)$ & $8.10 \pm 0.08$ & $3.60 \pm 0.03$ & $4.00 \pm 0.03$ \\
\hline
\end{tabular}

Table 3: Textural properties of the three kinds of scaffolds

\begin{tabular}{|c|c|c|c|}
\hline Material & Wave number $\left(\mathrm{cm}^{-1}\right)$ & Group assignment & References \\
\hline Chitosan & $1900-1500$ & Amide I: $v \mathrm{C}=\mathrm{O}$ & {$[31]$} \\
\hline
\end{tabular}




\begin{tabular}{|c|c|c|c|}
\hline Chitosan & $1650-1550,1570-1515$ & $\delta \mathrm{N}-\mathrm{H}(\mathrm{I}), \delta \mathrm{N}-\mathrm{H}(\mathrm{II})$ & {$[31]$} \\
\hline Chitosan & $1154-896$ & $\delta \mathrm{COC}($ saccharide- $\beta-1-4)$ & {$[31]$} \\
\hline Chitosan & $1300-1000$ & $\mathrm{C}-\mathrm{O}$ (cyclic) & {$[31]$} \\
\hline BG & $1350-1080$ & $\mathrm{P}=\mathrm{O}$ Stretch & {$[32]$} \\
\hline BG & $940-860$ & Si-O-Si Stretch & {$[32]$} \\
\hline BG & $890-800$ & C-O Stretch & {$[32]$} \\
\hline BG & $1175-710$ & Si-O-Si Tetrahedral & {$[32]$} \\
\hline BG & $560-550$ & P-O Bend & {$[32]$} \\
\hline BG & $540-415$ & Si-O-Si Bend & {$[32]$} \\
\hline
\end{tabular}

Table 4: Major vibration bands associated with chitosan and bioactive glass

\begin{tabular}{|c|c|c|c|}
\hline Scaffolds 1\% & \multicolumn{3}{|c|}{$C_{g}=C_{0} \times\left[1-\exp \left(-\frac{t}{\tau}\right)\right]$} \\
\hline & $\mathrm{C}_{0}(\mathrm{mg} / \mathrm{mL})$ & $\tau$ (minutes) & \multicolumn{2}{|c|}{ Laws } \\
\hline $1 \mathrm{CH}: 2 \mathrm{BG}$ & $1.90 \pm 0.01$ & 29 & $C_{g}=1.90 \times\left[1-\exp \left(-\frac{t}{29}\right)\right]$ \\
\hline $1 \mathrm{CH}: 1 \mathrm{BG}$ & $4.00 \pm 0.01$ & 30 & $C_{g}=4.00 \times\left[1-\exp \left(-\frac{t}{30}\right)\right]$ \\
\hline $2 \mathrm{CH}: 1 \mathrm{BG}$ & $6.20 \pm 0.01$ & 28 & $C_{g}=6.20 \times\left[1-\exp \left(-\frac{t}{28}\right)\right]$ \\
\hline
\end{tabular}

Table 5: Laws of kinetics for scaffolds with $1 \%$ of gentamicin
Scaffolds 3\%
$C_{g}=C_{0} \times\left[1-\exp \left(-\frac{t}{\tau}\right)\right]$ 


\begin{tabular}{|c|c|c|c|}
\hline & $\mathrm{C}_{0}(\mathrm{mg} / \mathrm{mL})$ & $\tau$ (minutes) & Laws \\
\hline $1 \mathrm{CH}: 2 \mathrm{BG}$ & $6.00 \pm 0.01$ & 38 & $C_{g}=6.00 \times\left[1-\exp \left(-\frac{t}{38}\right)\right]$ \\
\hline $1 \mathrm{CH}: 1 \mathrm{BG}$ & $6.30 \pm 0.01$ & 38 & $C_{g}=6.30 \times\left[1-\exp \left(-\frac{t}{38}\right)\right]$ \\
\hline $2 \mathrm{CH}: 1 \mathrm{BG}$ & $12.40 \pm 0.01$ & 38 & $C_{g}=12.40 \times\left[1-\exp \left(-\frac{t}{38}\right)\right]$ \\
\hline
\end{tabular}

Table 6: Laws of kinetics for scaffolds with 3\% of gentamicin 